\title{
Strategies and Technology for Managing High-Carbon Ash
}

Technical Progress

Report for the Period:

Principal authors:

Report Issue Date:

DOE Award Number:

Submitting Organization(s): Brown University (R. Hurt)

Division of Engineering, Box D

Providence, RI 02912

University of Utah

Department of Chemical and Fuels Engineering

Salt Lake City, Utah 


\section{Disclaimer}

This report was prepared as an account of work sponsored by an agency of the United States Government. Neither the United States Government nor any agency thereof, nor any of their employees, makes any warranty, express of implied, or assumes any legal liability or responsibility for the accuracy, completeness, or usefulness of any information, apparatus, product, or process disclosed, or represents that its use would not infringe privately owned rights. Reference herein to any specific commercial product, process, or service by trade name, trademark, manufacturer, or otherwise does not necessarily constitute or imply its endorsement, recommendation, or favoring by the United States Government or any agency thereof. The views and opinions of authors expressed herein do not necessarily state or reflect those of the United States Government or any agency thereof. 


\begin{abstract}
The overall objective of the present project is to identify and assess strategies and solutions for the management of industry problems related to carbon in ash. Specific research issues to be addressed include:

- the effect of parent fuel selection on ash properties and adsorptivity, including a first ever examination of the air entrainment behavior of ashes from alternative (non-coal) fuels.

- the effect of various low-NOx firing modes on ash properties and adsorptivity

- the kinetics and mechanism of ash ozonation. This data will provide scientific and engineering support of the ongoing process development activities.

This first project period, experiments were carried out to better understand the fundamental nature of the ozonation effect on ash. Carbon surfaces were characterized by surfactant adsorption, and by X-ray Photoelectron Spectroscopy before and after oxidation, both by air at $440 \mathrm{C}$ and by ozone at room temperature. The results strongly suggest that the beneficial effect of ozonation is in large part due to chemical modification of the carbon surfaces.
\end{abstract}




\section{TABLE OF CONTENTS}

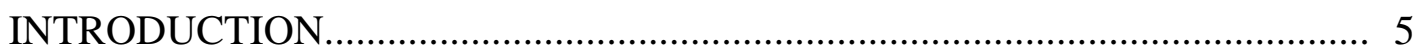

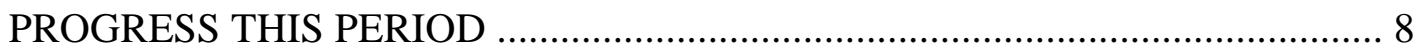

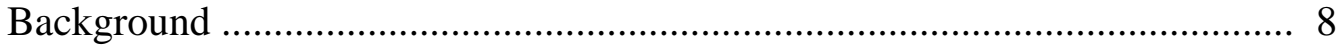

Materials and Experimental Procedures..................................................... 9

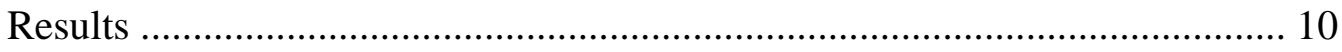

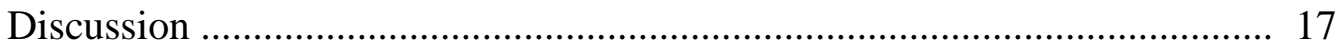



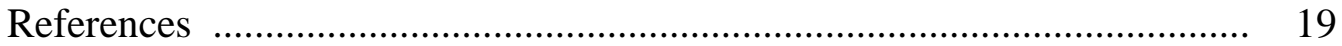




\section{INTRODUCTION}

Pulverized coal combustion produces over 75 million tons of fly ash and bottom ash in the U.S. every year. The most widespread and economically attractive option for utilizing fly ash is in concrete manufacture, where the fly ash serves as a partial replacement for Portland cement. In most concrete mixtures, specialty surfactants, or "air entraining admixtures" (AEAs), are added to stabilize sub-millimeter air bubbles, which improve resistance to freeze / thaw cycles (see Fig. 1). The bubbles are believed to provide excess volume to accommodate the expansion of residual water upon freezing in the set concrete. Solid carbon residues, if present in fly ash in high concentration, can adsorb these surfactants and render them unable to fulfill their intended function (see Fig. 2). As a result the stable air volume is too low or the mean bubble separation (spacing factor) is too high to impart the desired freeze/thaw resistance.

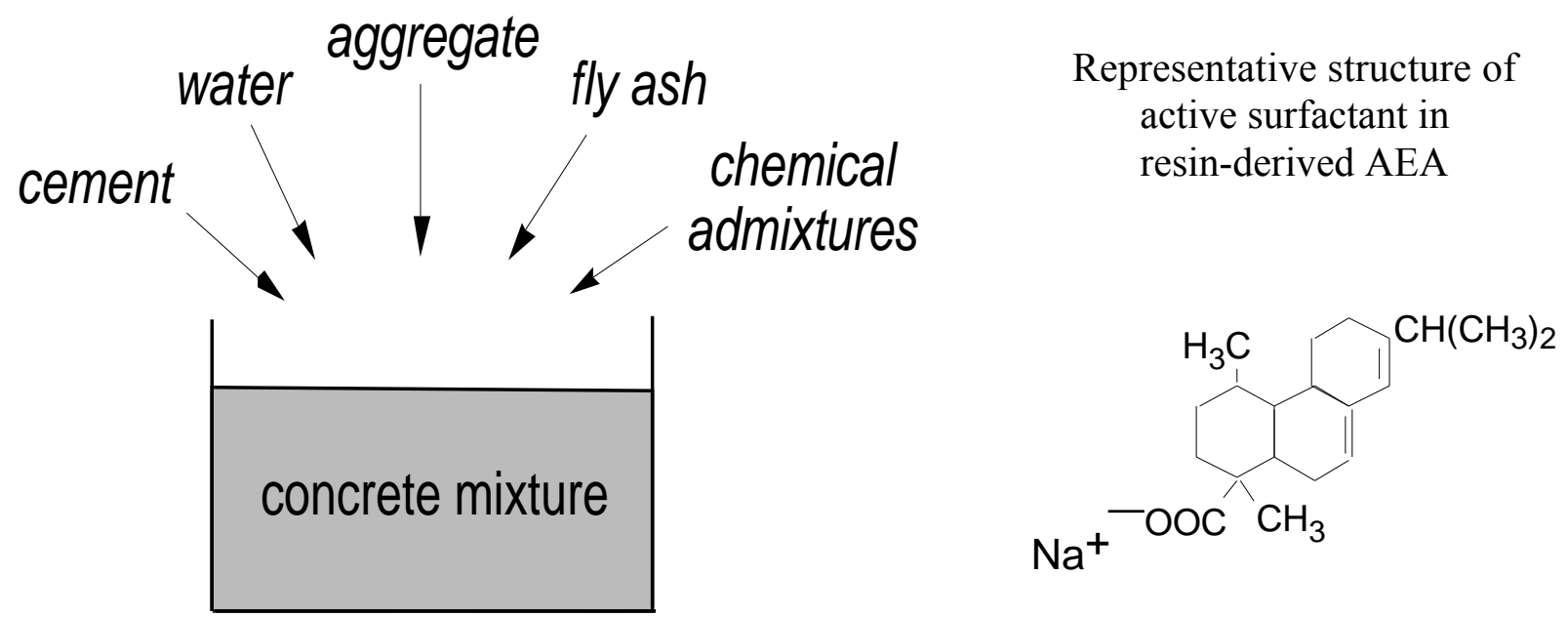

Figure 1. Overview of the composition of fly ash concrete. One class of chemical admixtures are air entraining admixtures (AEA), for which a model structure is shown.

Although increasing surfactant dose may compensate for the adsorption loss, large surfactant doses in practice lead to large and intolerable variations in entrained air when normal variations in ash properties are encountered in the field. Current regulations in the U.S. limit the carbon content in ash streams for concrete applications to 2 to 6 weight-\%, depending on region and regulatory body. Carbon content is typically measured by the ASTM Loss-on-Ignition (LOI) test, which reports the extent of weight loss during air oxidation at 700 oC. At high levels, carbon can discolor concrete, or lead to loss of strength, but the first problem encountered as carbon level rises is poor air entrainment behavior and this is the primary driving force for the current regulations. If the air entrainment problem could be solved in some way, most ashes generated in the U.S. today would be utilized in concrete, even with current carbon levels.

Almost without exception, combustion research focuses on the amount of char consumed and the mass of unburned carbon in ash. Recent studies, however have observed variations in the surfactant adsorptivity of commercial ash samples that cannot be explained by variations in the amount of carbon present, but are related to variations in specific carbon properties such as surface 


\section{Surfactant adsorption sites}

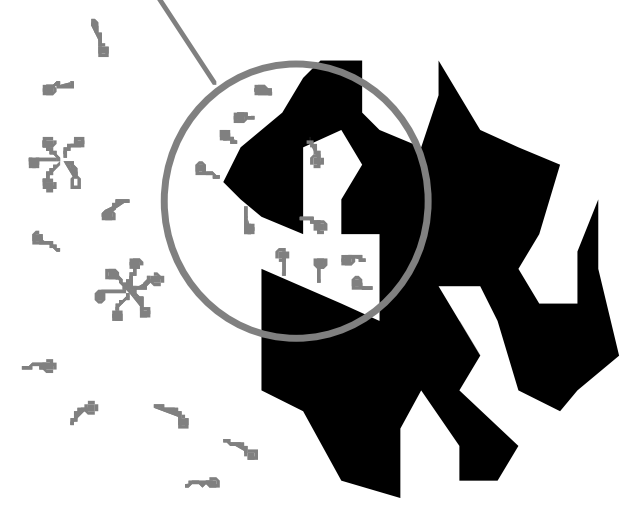

Figure 2. Surfactant adsorption on porous unburned carbon.

area, surface chemistry, and particle size. Very little is known about the effect of combustion conditions, coal type, and post-combustion treatment on carbon adsorptive properties. Several recent studies have measured the relevant adsorptive properties of commercial ash samples, but these samples come from complex and incompletely characterized combustion environments, and, as a result, it has not yet been possible to link surfactant adsorptivity to specific combustion conditions or fuel type.

A number of research and development groups are taking another approach to the carbon problem - they are developing technologies for the physical separation of carbon from the inorganic matter in ash, or for the burnout of carbon in dedicated combustion processes downstream of the boiler. These processes have not been widely adopted in the utility industry, largely due to capital cost and complexity. An alternative to these technologies is the use of ozone as described in the recent Brown University patent (US Patent 6136089). Ozonation at or near room temperature introduces oxygenated surface groups on the unburned carbon surfaces that increase the polarity of the carbon surfaces and reduce the surfactant adsorptivity, without removing significant carbon by full oxidation. In this respect the ozonation process is fundamentally different from all other proposed processes, including those in which carbon is burned out in a separate combustion process downstream of the primary coal-fired boiler. Potential advantages of ozonation include:

- simplicity of concept and operation

- operation under dry conditions, thus preserving the pozzolanic properties of ash.

- operation at ambient temperature, avoiding the need for a heat source.

- low estimated operating costs, consisting primarily of electricity.

- large-scale ozone generation is proven, off-the-shelf technology applied in water treatment, bleaching and disinfecting operations. 
- ozonation does not generate a high-carbon waste stream (as do separation processes), which in most cases must be landfilled

Potential disadvantages of ozonation are:

- ozone is toxic and must be handled in sealed units (note however that ash is already handled in sealed units to prevent dust emissions)

- process leaves carbon in place, thus leaving regulatory hurdles based on LOI in some cases. Even after treatment, if the ash contains carbon above the governing local or federal limit (typically 3 or $4 \%$ ), additional work is needed to verify its technical suitability for concrete, at least under current regulations.

The second cited disadvantage indicates that the most promising ash streams for initial demonstration are those that meet local LOI specifications, but still behavior poorly in concrete. We have identified a number of such field samples, typically class $C$ ashes, and have focused early work on their treatment. It is anticipated, however, that successful with these low-carbon samples will allow even higher carbon-content ash streams to be considered in the second round of applications.

EPRI is funding the practical development of the ozone technology, but more laboratory work is needed on the kinetics and mechanism to provide the scientific and engineering data for intelligent scale-up and optimization.

\section{Project Objective}

The overall objective of the present project is to identify and assess strategies and solutions for the management of industry problems related to carbon in ash. Options for improving or maintaining ash quality include:

- targeted fuel selection (or switching)

- modifications to combustion conditions or ash storage conditions

- post-combustion carbon surface modification by dry ozone

This project brings together a team of researchers from Brown University, the University of Utah, and Southern Company to address the problem of high carbon ash through a combination of bench scale experiments, pilot scale combustion trials with extensive analysis of collected ash samples, and the characterization of field ash samples. Specific scientific issues to be addressed include:

- the effect of parent fuel selection on ash properties and adsorptivity, including a first ever examination of the air entrainment behavior of ashes from alternative (non-coal) fuels.

- the effect of various low-NOx firing modes on ash properties and adsorptivity

- the kinetics and mechanism of ash ozonation. This data will provide scientific and engineering support of the ongoing process development activities.

Data from the project will be transferred to industry thorugh close interaction with EPRI and its member companies, the ozonation development team of PCI-Wedeco / Brown and selected ash marketing firms, and Southern Company. 


\section{PROGRESS THIS PERIOD}

Major progress was made this period on elucidating the role of firing conditions and fuel type on the quality of fly ash for concrete. Pilot-scale results from the University of Utah were combined with laboratory results from Brown to isolate the separate roles of fuel type and firing conditions. Addition of analyses from full-scale samples has led to a manuscript that provides the first detailed picture of the factors determining ash quality in real combustion systems. Special insight was obtained on the mechanisms through which low-NOx combustion degrades ash quality.

The detailed report that follows is based on a manuscript under preparation for journal submission. The actual manuscript has been submitted to the DOE for separate review, as required in the research contract.

\section{Detailed Report on The Effect of Fuel Type and Combustion Conditions on Residual Carbon Properties and Fly Ash Quality}

\section{Background}

Incomplete combustion of pulverized fuel can lead to significant decreases in thermal efficiency, operational problems with electrostatic precipitators, increased landfill volume for ash disposal, and loss of fly ash marketability. The high burnout efficiencies of most modern plants (>99.5\%) leave only modest room for improvement in efficiency, so much of the interest in residual carbon stems from problems with ash utilization in concrete. In fly ash concrete, carbon is an impurity that can discolor, increase water demand, and interfere with air entrainment. In some regions of the world the most serious problem with carbon is its undesirable effect on the air entrainment process. Carbon adsorbs the surfactants or "air entraining admixtures" used to stabilize air bubbles that impart freeze/thaw resistance in the set concrete[1-4].

Chronic problems with residual carbon in commercial ash samples have prompted a significant research effort over the last several years on various aspects of the problem, including techniques for predicting residual carbon levels [5-7], material properties of residual carbon[8], postcombustion processes for carbon/ash separation or low-temperature burnout[9], processes for carbon surface passivation to improve air entrainment behavior in fly ash concrete[10], and novel uses for high carbon ash or for concentrated residual carbon streams[11]. A series of recent studies on commercial ash samples has attempted to relate fly ash quality (surfactant adsorptivity) to residual carbon properties, such as surface area, surface chemistry, and pore size distribution[24]. This cited work does not provide direct answers to two important practical questions: how are adsorptivity and other residual carbon properties influenced by (1) solid fuel type, and (2) combustion conditions. These two questions lie in the realm of combustion science, a field that has not yet turned its attention to the issue of residual carbon properties. There are no measurements of residual carbon properties for a wide range of fuel types, nor for different temperature or oxygen histories experienced by a given fuel. Regarding firing conditions, a key unanswered question is the mechanism of unburned carbon formation in low- $\mathrm{NO}_{\mathrm{x}}$ systems. Are the residual carbon problems widely observed after low- $\mathrm{NO}_{\mathrm{x}}$ retrofits exclusively due to increased amounts of carbon in ash, or are chars formed in low- $\mathrm{NO}_{\mathrm{x}}$ flames also highly adsorptive and thus intrinsically "bad"?

The present work address the effects of fuel and firing conditions on residual carbon properties by combining (1) laboratory-scale experiments on a range of fuels under common conditions, (2) 
pilot-scale experiments on a single burner facility operated in high and low- $\mathrm{NO}_{\mathrm{x}}$ firing modes, and (3) the analysis of a large set of ash samples from full-scale commercial units.

\section{Materials and Experimental Procedures}

Table 1 gives properties of the solid fuels used in the bench- and pilot-scale experiments. In addition a set of 53 commercial ash samples were acquired from North American utility companies burning a range of bituminous and sub-bituminous coals[12]. One sample originated from a coal/petroleum-coke cofiring test burn described previously[3]. Selected measurements were also made on commercial carbon blacks (Cabot, Billerica, MA) as model materials for studying the effects of carbon surface oxides by X-ray Photoelectron Spectroscopy (XPS) in the absence of interference from the abundant inorganic oxides in ash.

Table 1.

Properties of Laboratory and Pilot-Scale Fuel Samples

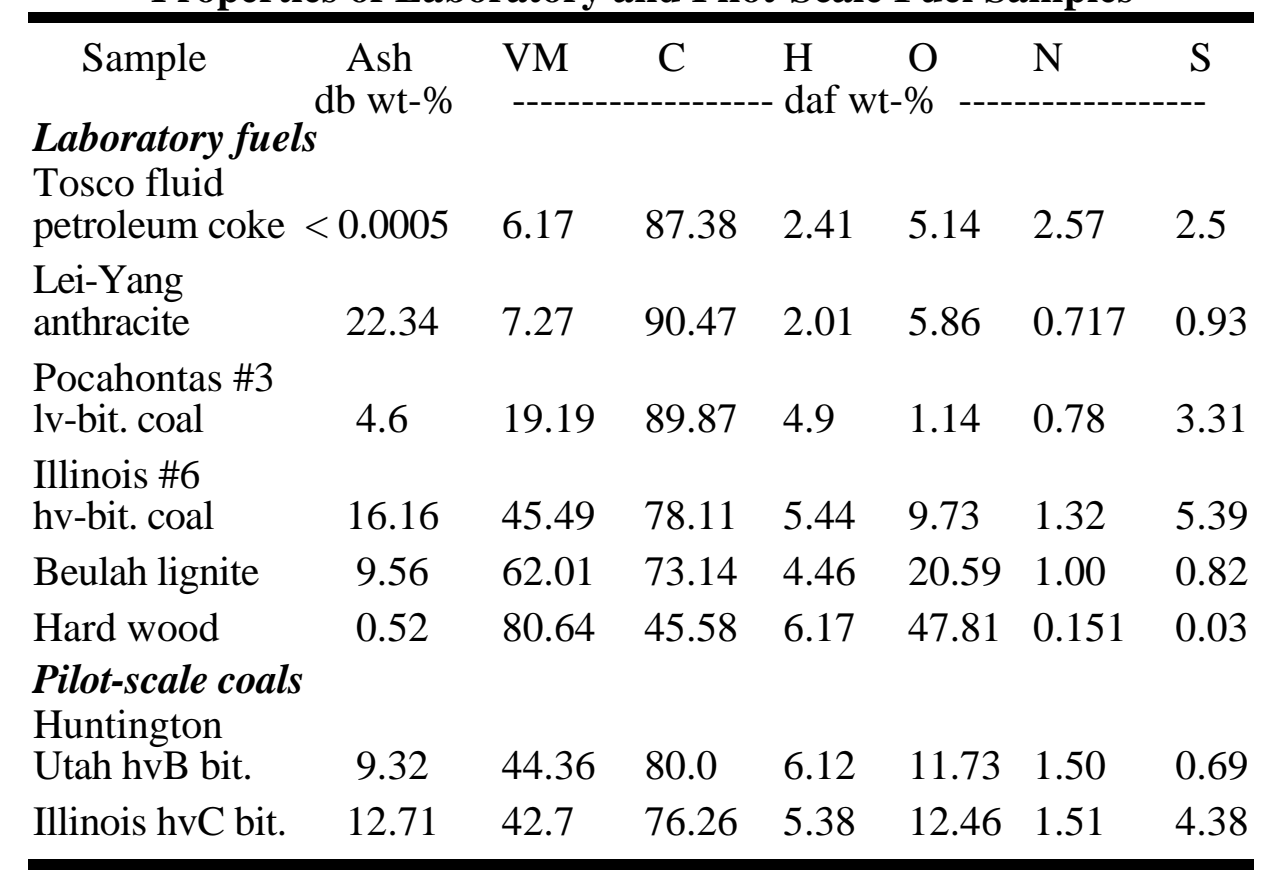

Pilot-scale experiments in different high- and low- $\mathrm{NO}_{\mathrm{x}}$ firing modes were carried out in a 29-kW, down-fired, U-shaped furnace with an inside diameter of $0.17 \mathrm{~m}$ and an overall length of $7.3 \mathrm{~m}$. The furnace has a Reynolds number based on furnace diameter of 1000-2000 depending on stoichiometric ratio and temperature. The furnace was operated in unstaged, high- $\mathrm{NO}_{\mathrm{x}}$ mode and in various low- $\mathrm{NO}_{\mathrm{x}}$ modes with nominal $1.5 \mathrm{sec}$ residence time in the fuel-rich zone. Temperatures 2 $\mathrm{m}$ from the burner ranged from $1720-1800 \mathrm{~K}$ and the furnace exit oxygen concentrations were 34\%. The detailed furnace conditions are documented elsewhere[13]. The fly ash samples were collected by drawing the entire exit gas flow through a one-bag fabric filter.

In separate experiments partially combusted chars were generated from six pulverized solid fuels in a high-temperature entrained flow reactor by rapid-quench extractive sampling at residence times from $30-100 \mathrm{msec}$ by a procedure described elsewhere[14]. The reactor is fed by a Hencken 
burner (Research Technologies, Pleasanton, CA) fueled with a $\mathrm{CH}_{4} / \mathrm{O}_{2} / \mathrm{Ar}$ mixture, producing a hot gas stream with post-flame oxygen concentration 13 mole-\% oxygen (for the anthracite and coke) and 3 mol- $\%$ oxygen (for the wood and remaining coals). Centerline temperatures varied from $1300 \mathrm{~K}$ to $1650 \mathrm{~K}$ and the solids feed rate was limited to less than $1 \mathrm{gm} / \mathrm{hr}$, yielding dilute phase conditions in which particle-to-particle interaction is minimal. Finally, selected char and ash samples were surface oxidized by contact with ozone-containing air passed upward through a fixed bed of material as in Gao et al.[10], or by subjecting samples to slow air oxidation in an open alumina crucible placed in a muffle furnace.

For each of the laboratory-, pilot-, full-scale, and surface oxidized samples, surfactant adsorptivity was measured by a modified foam index test, which is a standard titration procedure involving calibrated volumetric addition of surfactant solution to a cement / ash mixture as described in detail elsewhere[2]. Char oxidation reactivities were measured by non-isothermal TGA using a heating rate of $30 \mathrm{~K} / \mathrm{sec}$ in air. The relative reactivities are reported as values of critical temperatures, $\mathrm{T}_{\mathrm{cr}}$, defined as the temperature at which the measured rate reaches $0.065 \mathrm{mg} / \mathrm{min}-\mathrm{mg}$-partially-reactedsample[15]. Under these conditions, the combustion rate is free from boundary layer or in-bed heat and mass transfer effects and thus represents a material property of the char sample. Nitrogen adsorption isotherms at $77 \mathrm{~K}$ were measured using an Autosorb vapor adsorption apparatus. Surface areas were computed using a 20 point BET algorithm and mesopore size distributions were computed from the Barrett, Joiner, and Hallenda (BJH) theory of simultaneous capillary condensation and multilayer adsorption[16]. The surface chemistry of raw, air oxidized, and ozonated carbon black samples was investigated by XPS carried out at Evans East Laboratories (East Windsor, New Jersey).

\section{RESULTS}

Properties of the 53 commercial scale ash samples are summarized in Figs. 1 and 2. Residual carbon in class $\mathrm{C}$ ashes (primarily from sub-bituminous coals) tends to have a significantly higher combustion reactivity (low $\mathrm{T}_{\mathrm{cr}}$ in Fig. 1) and higher surface areas (Fig. 2) than residual carbon in class $\mathrm{F}$ ashes (primarily from bituminous coals). Typical $\mathrm{T}_{\mathrm{cr}}$ values are $450 \mathrm{oC}$ (Class $\mathrm{C}$ ) and 600 $\mathrm{oC}$ (Class F), which corresponds to a reactivity ratio of about 65 when the data is brought to a common reference temperature using an activation energy of $35 \mathrm{kcal} / \mathrm{mol}$. This is a very significant reactivity difference and implies that in the secondary carbon burnout processes currently under development, class $\mathrm{C}$ ashes can be beneficiated at significantly lower temperatures than class $\mathrm{F}$ ashes. The higher areas of sub-bituminous carbon residues also make them more attractive as inexpensive environmental sorbents, but this advantage is diminished in practice since their high reactivity typically leads to high burnout and lower carbon contents (LOI) relative to class F ashes as seen in Fig. 2. 


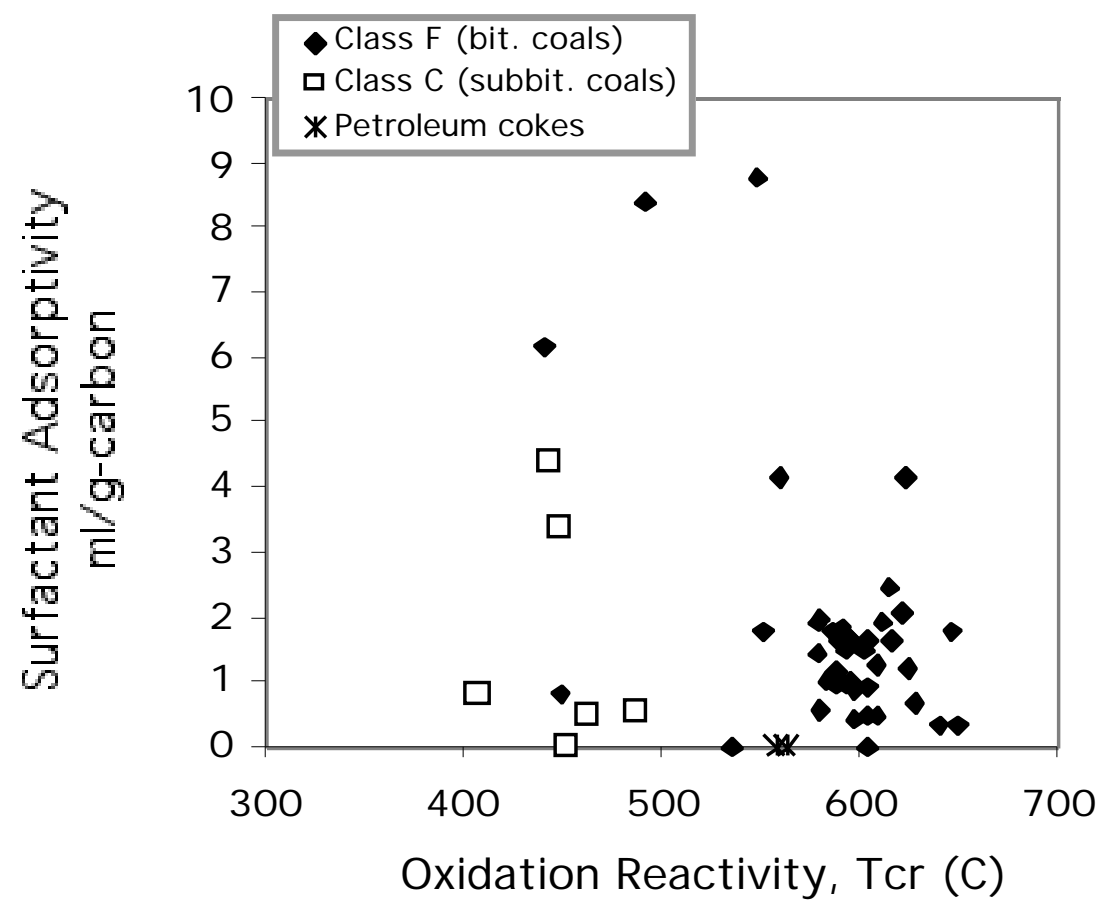

Figure 1. Combustion reactivities of residual carbon in 53 commercial pulverized fuel ash samples expressed as critical temperatures, $\mathrm{T}_{\mathrm{cr}}$ values, derived from non-isothermal TGA experiments.

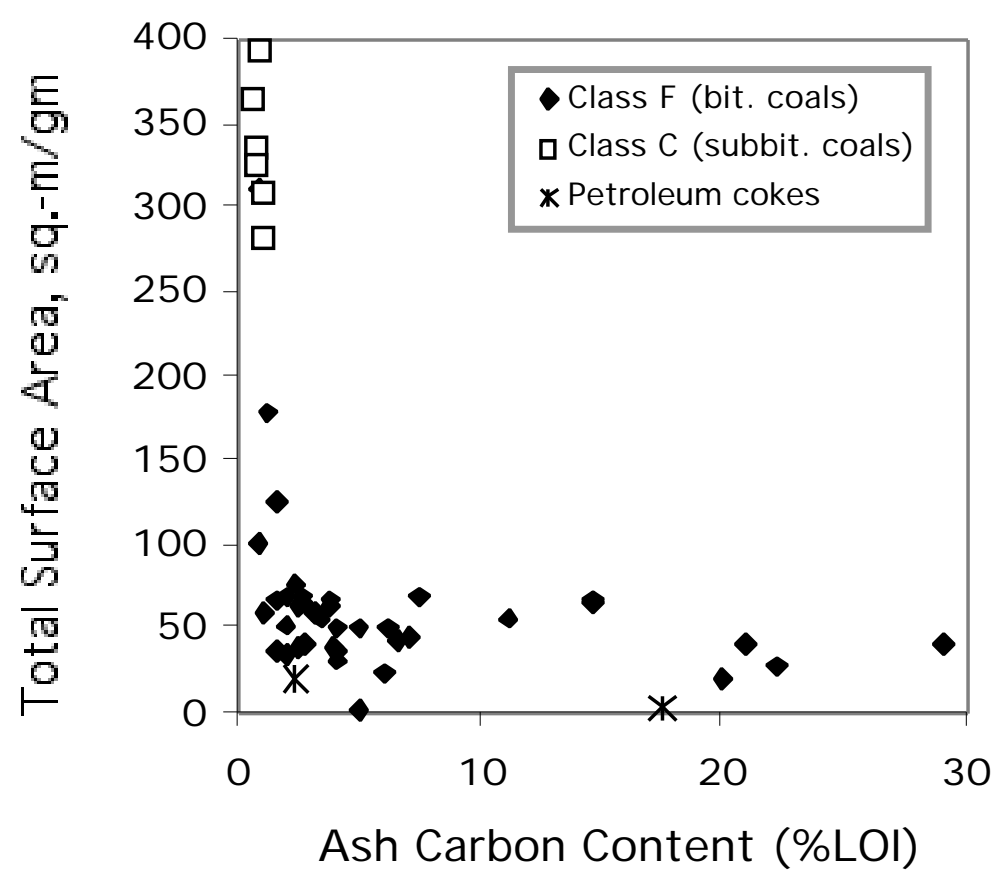

Figure 2. Surface areas of residual carbon in commercial ash samples determined by application of the BET theory to nitrogen adsorption isotherms at $77 \mathrm{~K}$. The areas of the mineral portion of the ash were determined separately after oxidative removal of the carbon, and the values subtracted to isolate the specific carbon area. LOI is "Loss-on-Ignition" a standard approximate measure of carbon content in ash defined as the percentage mass loss during slow air oxidation at $750 \mathrm{oC}$. 
Data from the laboratory portion of this study is summarized in Figs. 3-5 and Table 2. The highheating-rate laboratory chars show total surface areas that increase monotonically with decreasing carbon content of the parent fuel. The surfactant adsorptivity shows a similar trend, increasing with decreasing carbon content from an immeasurably small value for petroleum coke to about $4 \mathrm{ml} / \mathrm{g}$ carbon for the mid-rank coal char, but then decreasing to $1.7 \mathrm{ml} / \mathrm{gm}$ for the hard wood char. Fig. 4 shows that a better correlation is obtained when adsorptivity is plotted vs the surface area in pores larger than $2 \mathrm{~nm}$ determined by application of the BJH theory to the complete nitrogen isotherm. This is consistent with previous work on other carbon materials[3], in which it was shown that the utilization of micropores was incomplete in the standard surfactant adsorptivity test due to slow liquid phase diffusion of the large surfactant molecules[3].

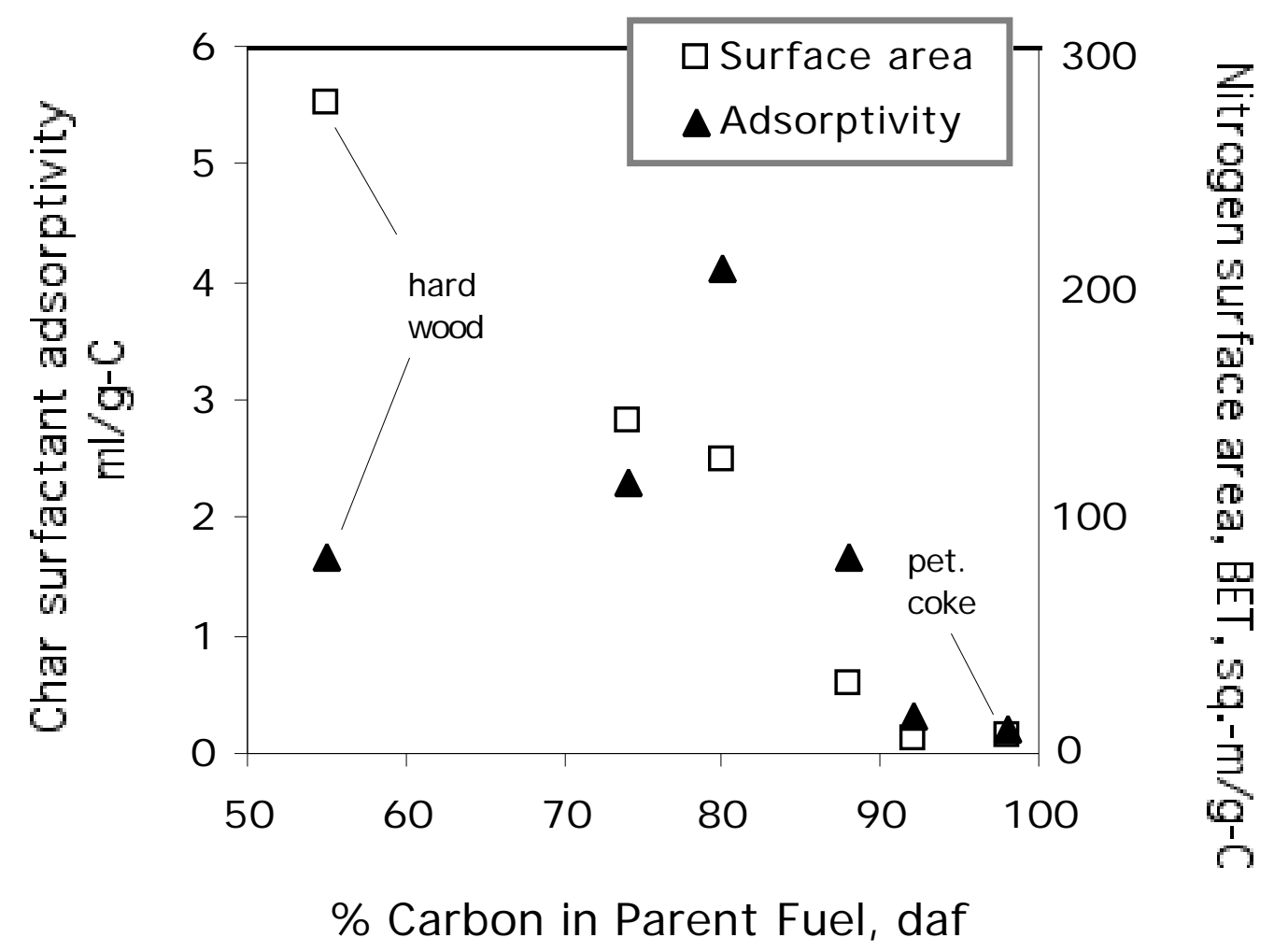

Figure 3. Surfactant adsorptivity and nitrogen BET surface area of various solid fuel chars (from upper portion of Table 1) prepared at high heating rates $\left(\sim 5.10^{4} \mathrm{sec}^{-1}\right)$ under standard conditions in a laboratory entrained flow reactor. Fuels are coals of various rank except where noted. 




Figure 4. Surfactant adsorptivity vs. the sum of mesopore and macropore area (area in pores larger than $20 \mathrm{~nm}$, from BJH theory applied to the nitrogen isotherm) in the laboratory generated chars from Fig. 3. Surfactant adsorptivity correlates better with this non-microporous area than with total surface area which is much higher in some char samples.

Table 2 and Fig. 5 present results on the effect of carbon surface chemistry. Oxidation by air at $440{ }^{\circ} \mathrm{C}$ or by ozone at $20{ }^{\circ} \mathrm{C}$ both decrease adsorptivity consistent with previous observations[10]. Data in Table 2 further demonstrate the reversibility of the process - heating to $1000 \mathrm{C}$ to remove surface oxides recovers $80 \%$ of the adsorptivity (Table 2). It is difficult to characterize surface oxide groups by spectroscopic techniques in the presence of the abundant oxide minerals in ash. For this reason selected experiments were carried out on carbon black as a model carbon material with very low amounts of inorganic oxides. First Fig. 5 and Table 2 show that carbon black samples respond to surface oxidation in the same way as residual carbon - both air and ozone treatment decrease adsorptivity to much lower values. Secondly, XPS results in Table 2 show greatly enhanced atomic oxygen contents in the near-surface regions (penetration depth $\sim 12 \mathrm{~nm}$ ) of carbon black samples ozonated under the same conditions used for fly ash carbon. Highresolution spectral analysis of the high-binding energy tail of the C1s peak reveals increases in C$\mathrm{O}, \mathrm{C}=\mathrm{O}$, and $\mathrm{O}-\mathrm{C}=\mathrm{O}$ functionalities with only subtle differences between thermal (air) oxidation and ozonation. 


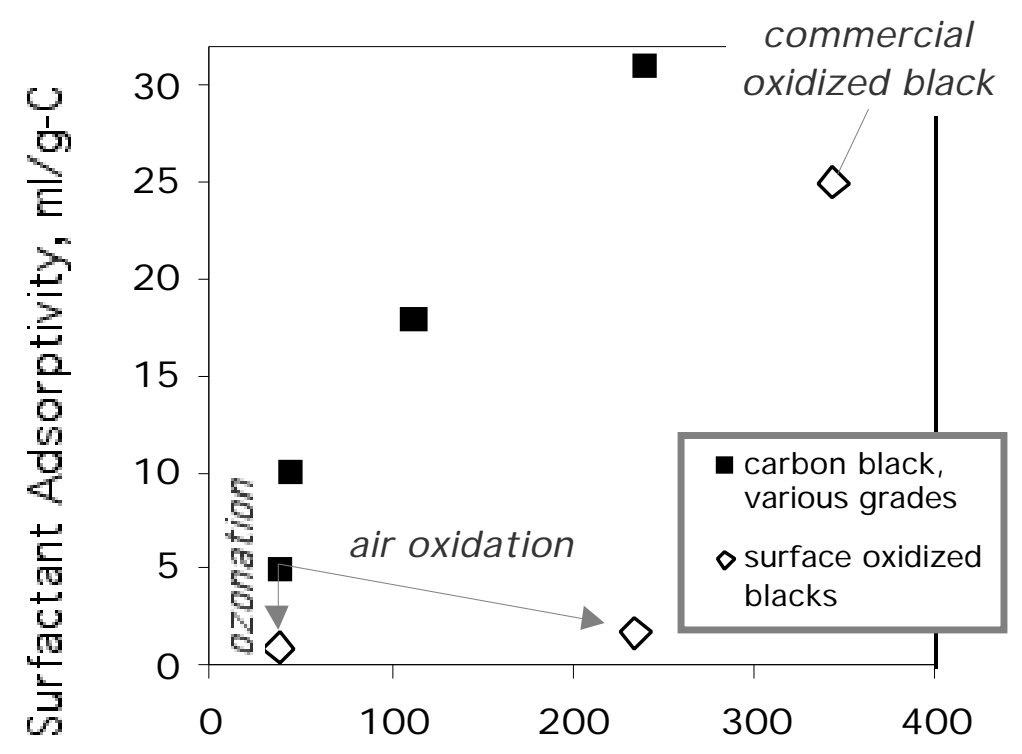

Carbon Surface Area, sq.-m/ g-carbon

Figure 5. Effect of surface oxidation on total surface area and surfactant adsorptivity for carbon blacks as model materials. For carbon blacks, total area either increases or remains the same during oxidation, while surfactant adsorptivity decreases, a result that unambiguously identifies surface chemistry changes (rather than total area loss) as the primary mechanism of adsorption inhibition.

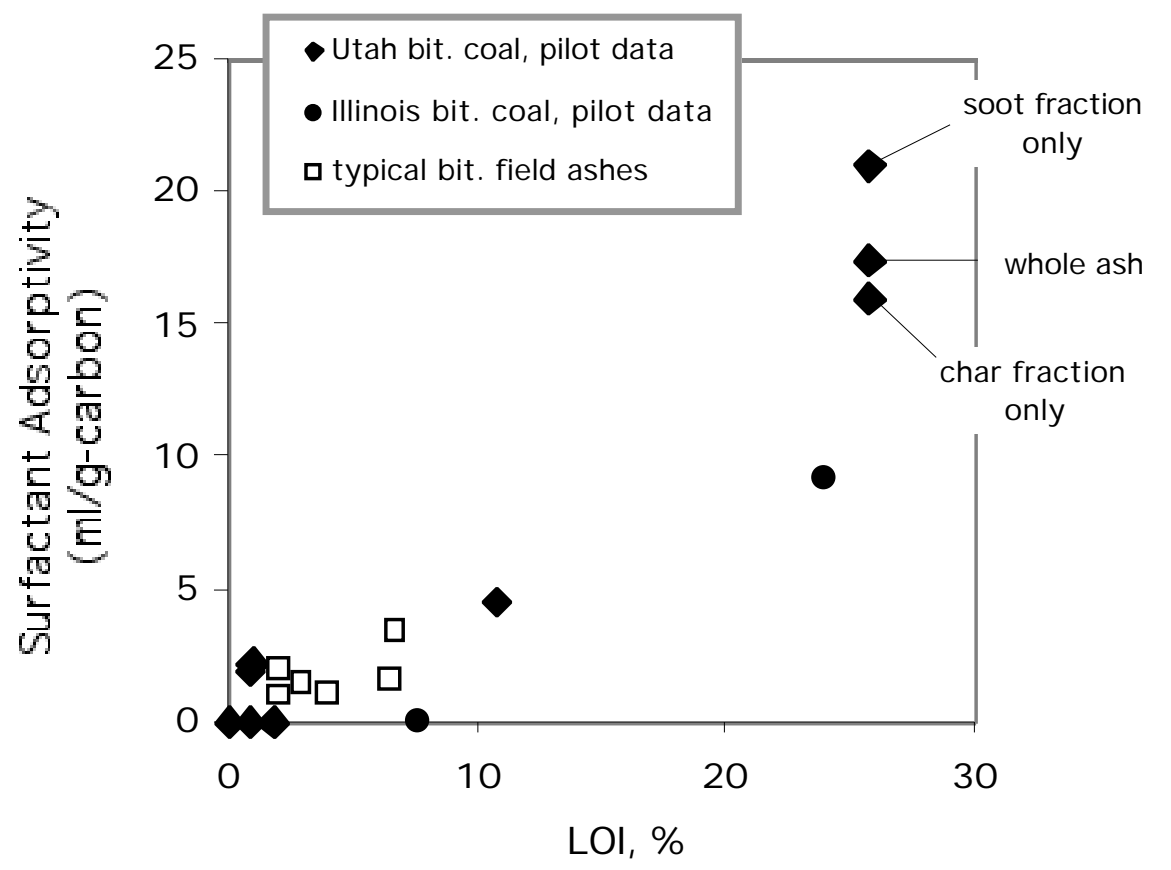

Figure 6. Pilot scale data on two coals burned in high- $\mathrm{NO}_{\mathrm{x}}$ firing mode and in several different low- $\mathrm{NO}_{\mathrm{x}}$ firing modes. As LOI (carbon content) of ash increases, the specific carbon activity toward surfactants also tends to increase. Separate contributions of soot and char from the highest LOI sample were determined using the fine particulate separation scheme of Veranth et al.[16]. 
The pilot-scale results are presented in Figs. 6-9 for a variety of low- $\mathrm{NO}_{\mathrm{x}}$ and high- $\mathrm{NO}_{\mathrm{x}}$ firing modes. Figure 6 shows that surfactant adsorptivity of the carbon residues from the U-furnace varies greatly, and tends to be higher for samples with poor burnout (high LOI). The combination of high LOI (gm-carbon/g-ash) and high specific adsorptivity (ml surfactant / g-carbon) makes the total adsorptivity of some of these ash samples (ml/g-ash) extremely high. The good superposition of data from commercial bituminous coal ash suggests that the U-furnace is a reasonable simulator of larger furnaces with respect to unburned carbon properties. Separation of char and soot from the very high LOI sample as described previously[17] shows that the fine carbonaceous fraction has a higher surfactant adsorptivity, though both the fine and coarse fractions contribute significantly.

Most of the high-LOI, high adsorptivity samples in Fig. 6 come from low-NO $\mathrm{N}_{\mathrm{x}}$ firing, but Fig. 7 shows that $\mathrm{NO}_{\mathrm{x}}$ alone is not a good indicator of ash quality. In particular, low- $\mathrm{NO}_{\mathrm{x}}$ firing modes can produce carbon with very high or very low adsorptive power. Figure 8 shows a good correlation between surface area and burnout (LOI) for the pilot-scale samples. Figure 9 shows a good correlation between surfactant adsorptivity and carbon surface area among the pilot-scale samples.



Figure 7. Pilot scale results giving residual carbon surfactant adsorptivity vs. $\mathrm{NO}_{\mathrm{x}}$ at furnace exit. The low- $\mathrm{NO}_{\mathrm{x}}$ carbons exhibit a wide range of activities making $\mathrm{NO}_{\mathrm{x}}$ alone a poor indicator of carbon adsorptivity or ash quality. 


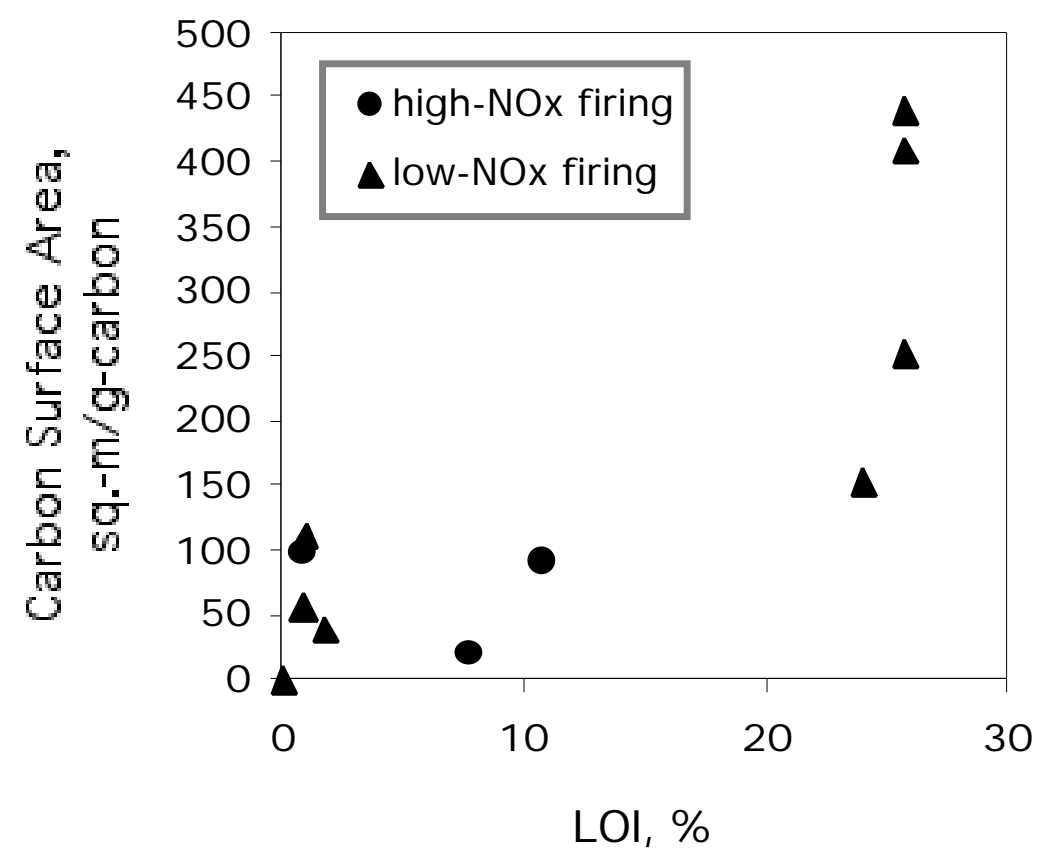

Figure 8. Pilot-scale results: residual carbon surface area (nitrogen BET) vs. ash carbon content (\% LOI). Poor burnout (high LOI) generally leads to a high surface area residual carbon.



Figure 9. Pilot-scale results: residual carbon surfactant adsorptivity vs. carbon surface area (nitrogen BET). High surface area is the most important contributing factor to high surfactant adsorptivity (poor ash quality) in the pilot-scale samples. 


\section{DISCUSSION}

The present work establishes that unburned carbon properties are very sensitive to both fuel type and combustion conditions when care is taken to vary them independently. Because surfactant adsorptivity is the primary variable determining ash quality for concrete, we attempt to understand its behavior in detail below by separate consideration of three factors that co-determine its value: (1) carbon surface area, (2) accessibility of that surface for the large surfactant molecules, and (3) surface chemistry.

Carbon surface area. Residual carbon surface area decreases with increasing carbon content in the parent fuel, as expected, and also decreases with increasing burnout at the pilot-scale. This latter trend is consistent with decreasing surface areas during combustion at high temperature observed in several laboratory studies[2,14] and is the opposite of the behavior observed during low temperature combustion, which typically "activates" or increases the specific surface of carbon materials. The largest contributing factor to high adsorptivity among the pilot-scale samples is high carbon surface area (Fig. 9), which generally occurs in samples with poor overall burnout (Fig. 8).

Surface accessibility. The role of surface accessibility is illustrated by the improvement in the adsorptivity / area correlation when only mesopore and macropore area $\left(\mathrm{d}_{\text {pore }}>2 \mathrm{~nm}\right)$ is counted (Fig. 4). It is also illustrated by the high specific adsorptivity of soot, whose area lies on the external surface of nanophase particles and is thus non-microporous and highly accessible. This argument based on soot structure is confirmed by the vapor adsorption data: the BJH meso- plus macropore area of soot is $34.5 \mathrm{~m} 2 / \mathrm{g}$, which is almost as high as the total BET area of $38.3 \mathrm{~m} 2 / \mathrm{g}$ indicating very little microporosity in soot and thus easy access by large surfactant molecules in solution.

Surface chemistry. The present data provide clear insight into role of surface oxides. First, the effect of ozone treatment is reversible when the samples are heated to a temperature sufficient to desorb the surface oxides (1000 oC). Secondly, oxidation of carbon black decreases adsorptivity dramatically while total surface area is constant or increasing. This observation resolves the question raised in earlier work[10] which was based solely on analysis of residual carbons. Residual carbons experience large decreases in total area during ozonation[10], making it unclear whether surface polarity or loss of total area is the dominant mechanism suppressing surfactant adsorptivity. In carbon black, however, the dominant meso- and macroporosity on the external surfaces of the nano-phase primary particles cannot be easily blocked by adsorbed oxides and thus total surface area is not lost during oxidation. Here the key role of surface chemistry is unambiguously established for the first time.

These combined results demonstrate that surface oxides, arising from combustion or from postcombustion treatment, make residual carbon surface less adsorptive and improve ash quality. The underlying mechanism in the aqueous concrete medium is depicted in Fig. 10 and described in the caption. Simple adsorption / desorption arguments suggest that the surface oxide population on carbon will vary with the combustion conditions, being lowest in hot, fuel-rich (reducing) zones which promote desorption, and highest during low temperature oxidation where an extensive stable oxide film builds up over the course of conversion[17]. Variations in native oxide content are thus believed to contribute to the observed variability in adsorptivity. Further, the hot, fuel-rich zones in 
low- $\mathrm{NO}_{\mathrm{x}}$ environments have the potential to produce non-polar, high-adsorptivity carbon (see below).

\section{Char Properties in Low-NOx Combustion}

These results taken together provide new insight into the mechanism by which low- $\mathrm{NO}_{\mathrm{x}}$ firing affects ash quality. Substantial field experience in North America has shown that installation of low- $\mathrm{NO}_{\mathrm{x}}$ burners and/or overfire air ports for fuel staging increases unburned carbon levels and leads to field reports of poor air entrainment behavior in most cases. An important unanswered question is whether the degradation of ash quality is due solely to the increased carbon content, or whether chars exposed to fuel-rich zones in the near-burner region are also intrinsically "bad" (highly adsorptive). Data in Fig. 7 and 9 clearly show that some low- $\mathrm{NO}_{\mathrm{x}}$ carbons are indeed intrinsically bad (have high adsorptivities per gram of carbon), but only those with poor overall burnout.

The following picture of low- $\mathrm{NO}_{\mathrm{x}}$ carbon formation emerges from this study. The fuel-rich nearburner zones in staged firing delay char consumption and degrade burnout, but also drive off carbon surface oxides. If downstream mixing is incomplete, fuel-rich packets persist in which lowconversion, high-area, low-oxide-content char, and in some cases soot[16], are carried into the fly ash making it highly adsorptive and of poor quality for ash utilization. In contrast, a staged low$\mathrm{NO}_{\mathrm{X}}$ system with good downstream mixing reintroduces oxygen to the char surfaces, where it accomplishes further conversion, destroys surface area, destroys soot, and returns the pseudosteady-state surface oxide population, effectively erasing the memory of the fuel-rich zone seen by the char surfaces in the near-burner zone. Thus low-NO $\mathrm{N}_{\mathrm{x}}$ ashes with good burnout (low LOI) are observed to often possess benign (low-adsorptivity) carbon, as directly observed in the pilot experiments described herein.



Figure 10. Sketch of aqueous phase interactions between concrete surfactants and carbon surfaces. Abietic acid anion is shown as a model compound representing the surfactant structures in concrete admixtures. The non-polar part of the surfactant molecule is shown adsorbing on the non-polar carbon surface(left), with which it interacts by dispersion forces, while the anionic part remains in aqueous solution. On polar carbon surfaces (right) these dispersion forces are too weak for the surfactant to displace water molecules, which have hydrogen bonded to surface oxide functionalities. Oxidation renders carbon surfaces hydrophilic - it is by this basic mechanism that air oxidation and ozonation decrease surfactant adsorptivity and improve ash quality for concrete applications. 


\section{CONCLUSIONS}

1. Solid fuel selection strongly influences residual carbon properties, including surface area, surfactant adsorptivity, and oxidation reactivity.

2. Carbon surfactant adsorptivity, the most important ash quality variable in some regions of the world, is strongly dependent on combustion conditions, as determined through pilotscale experiments in a single swirl burner facility operated in multiple firing modes on a given coal.

3. Surfactant adsorptivity is reduced by carbon surface oxidation occurring during combustion or during post-combustion treatment with air or ozone. Experiments on carbon black unambiguously demonstrate that increase in surface polarity and hydrophilicity is the governing mechanism.

4. Surfactant adsorptivity correlates much better with total burnout than with flue gas $\mathrm{NO}_{\mathrm{x}}$ levels, indicating that low- $\mathrm{NO}_{\mathrm{x}}$ chars are not all intrinsically "bad". Low- $\mathrm{NO}_{\mathrm{x}}$ flames can produce low-adsorptivity chars and high quality ash for utilization, provided downstream temperatures and secondary/tertiary air mixing are favorable for overall burnout. This result is encouraging for ash utilization from low- $\mathrm{NO}_{\mathrm{x}}$ technologies.

\section{References}

1. Helmuth, R. Fly Ash in Cement and Concrete, The Portland Cement Association, Skokie, Illinois, 1987.

2. Hachman, L., Burnett, A., Gao, Y., Hurt, R.H., and Suuberg, E.M. Proc. Comb. Inst. 27:2965 (1998).

3. Yu, J., Külaots, I., Sabanegh, N., Gao, Y., Hurt, R.H., Suuberg E.S., and Mehta, A., Energy and Fuels, 14:591 (2000).

4. Hill, R.L., Sarkar, S.L., Rathbone, R.F., and Hower, J.C., Cement and Concrete Research 27:193 (1997).

5. Pedersen L.S., Glarborg P., Dam-Johansen K., Hepburn P.W., and Hesselmann. G., Comb. Sci. Tech. 132:251(1998).

6. Cloke M., Lester, E., and Gibb, W. Fuel 76:1257(1997).

7. Walsh, P.M., Energy and Fuels, 11:965 (1997).

8. Maroto-Valer, M.M., Taulbee, D.N, and Hower, J.C. Fuel 80:795 (2001).

9. Ban, H., Li, T.X., Hower, J.C., Schaefer, J.L., and Stencel, J.M. Fuel 76:801(1997)

10. Gao, Y., Külaots, I., Chen, X., Aggarwal, R., Mehta, A., Suuberg, E.M., and Hurt, R.H., Fuel 80:765 (2001).

11. Maroto-Valer, M.M., Zhang, Y.Z., Andresen, J.M., Jones, A., and Morrison, J.L., Am. Chem. Soc. Div. Fuel Chem. Preprints 221:115 (2001).

12. Kualots, I. Ph.D. Thesis, Division of Engineering, Brown University, May, 2001. 
13. Veranth, J.M., Pershing, D.W., Sarofim, A.F., and Shield, J.E., Proc. Comb. Inst. 27:1737 (1998).

14. Davis, K.A., Hurt, R.H., Yang, N.Y.C., and Headley, T.H., Comb. and Flame 100:31 (1995).

15. Charpenay, S., Serio, M.A., and Solomon, P.R., Proc. Comb. Inst. 24:1189 (1992).

16. Barrett, E.P., Joyner, L.G., and Halenda, P.P., J. Am. Chem. Soc., 73:373 (1951).

17. Veranth, J.M., Fletcher, T.H., Persing, D.W., and Sarofim, A.F., Fuel 79:1067 (2000).

18. Lizzio, A.A., Piotrowski, A., Radovic, L.R., Fuel67:1691 (1988).

\section{FUTURE PLANS}

During the next period we will return our focus to ozonation as a beneficiation process for high carbon ash. We plan to carry out surface energy analysis by contact angle measurements using standard test liquids, and to combine this data with XPS, FTIR, and other surface characterization methods to explain the mechanism behind the remarkable effectiveness of ozone. 